\title{
En la rompiente: subjetividades arrancadas de la costa, subjetividades arrastradas a la costa. Conflictos socioterritoriales y socioambientales en torno al principal balneario uruguayo
}

\begin{abstract}
IN THE BREAKER. SUBJECTIVITIES PULLED FROM THE COAST, SUBJECTIVITIES DRAGGED TO THE COAST: SOCIO-TERRITORIAL AND SOCIO-ENVIRONMENTAL CONFLICTS AROUND URUGUAY'S MAIN TOURIST DESTINATION
\end{abstract}

NA DISJUNTOR: SUBJETIVIDADES ARRANCADAS DO LITORAL, SUBJETIVIDADES ARRASTADAS PARA O LITORAL CONFLITOS SÓCIO-TERRITORIAIS E SOCIOAMBIENTAIS EM TORNO DO PRINCIPAL BALNEÁRIO URUGUAIO

Eliane Gerber Comba *1

egerber@psico.edu.uy

\section{Resumen}

Se presentan a continuación dos grupos de relatos recolectados en diferentes trabajos de campo: una etnografía y un proceso de recolección de narrativas biográficas. Estos no han tenido como objetivo que los participantes produzcan material sobre las relaciones que mantienen con el ambiente, sin embargo, un hallazgo significativo ha sido la emergencia de esta temática como un núcleo de alto valor para los mismos. El presente artículo propone analizar las dimensiones subjetivas de dichas narrativas, cargadas de memoria ambiental, para aportar a la comprensión de los conflictos socioambientales y territoriales presentes en la zona Este del Uruguay. A pesar de la diversidad de sus trayectorias, tanto los habitantes de Maldonado y Punta del Este que se han visto empujados a dejar sus hogares junto a la costa, como los migrantes internos de bajos recursos, a quienes los primeros responsabilizan por la degradación urbana y ambiental, se constatan elementos comunes, subjetividades doloridas, que han debido ajustarse a una continua pérdida de los espacios que viven como propios. Al mismo tiempo, los migrantes dan cuenta de trayectorias a las que estas costas les han ofrecido una oportunidad de recomposición, donde los elementos estéticos del ambiente, en sentido amplio, juegan un rol significativo.

\footnotetext{
1 *Centro Universitario Región Este de la Universidad de la República
}

Tekoporá ${ }^{\circledR}$. Centro Universitario de la Región Este. Universidad de la República 
Palabras claves: Memoria ambiental, dolor subjetivo, conflictos socioambientales, conflictos socioterritoriales

\begin{abstract}
This paper presents the findings of groups of reports collected in two different fieldwork experiences: an ethnography and biographical narrative methodology. Neither had the initial objective of producing material about participant relationships with the environment, however, a significant finding has been the emergence of this topic as a nucleus of high value for them. This article proposes an analysis of the subjective dimensions of these narratives, which are loaded with environmental memory, to contribute to the understanding of the social, environmental and territorial conflicts present in the eastern region of Uruguay. Despite the diversity of their trajectories, both the inhabitants of Maldonado and Punta del Este who have been forced to leave their homes along the coast, as well as low-income internal migrants-whom the former blame for urban and environmental degradation-show the common element of painful subjectivities which have had to adjust to a continuous loss of personal lived space. At the same time, migrants give an account of trajectories in which these coasts have offered them an opportunity for recomposition, and where the esthetic elements of the environment, in a broad sense, play a significant role.
\end{abstract}

Keywords: Environmental memory, subjective pain, socio-environmental conflicts, socio-territorial conflicts

\title{
Resumo
}

Dois grupos de histórias coletadas em diferentes estudos de campo são apresentados a seguir: uma etnografia e um processo de coleta de narrativas biográficas. Estas não tiveram como objetivo que os participantes produzissem material sobre as relações que mantêm com o meio ambiente, porém, um achado significativo foi o surgimento deste tema como um núcleo de alto valor para eles. Este artigo propõe-se a analisar as dimensões subjetivas dessas narrativas, carregadas de memória ambiental, para contribuir com a compreensão dos conflitos socioambientais e territoriais presentes na zona oriental do Uruguai. Apesar da diversidade de suas trajetórias, tanto os moradores de Maldonado como de Punta del Este, obrigados a deixar suas casas no litoral, bem como os migrantes internos de baixa renda, a quem os primeiros culpam pela degradação urbana e ambiental, são elementos comuns. encontramos, subjetividades dolorosas, que tiveram que se ajustar a uma perda contínua dos espaços que vivem como seus. Ao mesmo tempo, os migrantes relatam trajetórias para as quais essas costas têm oferecido uma oportunidade de recomposição, onde os elementos estéticos do ambiente, em um sentido amplo, desempenham um papel significativo.

Palavras-chave: Memória ambiental, dor subjetiva, conflitos socioambientais, conflitos socioterritoriais 


\section{Introducción}

El primer grupo de relatos presentados pertenecen a una relectura del material recolectado en el trabajo de campo de la Tesis de Maestría en Psicología Social: Significados y usos de la alteridad. Una aproximación etnográfica a los procesos de producción de subjetividad vinculados a la movilidad geográfica en la ciudad de Maldonado (Gerber, 2016). El segundo grupo forma parte de los resultados alcanzados en el Proyecto: Trayectorias migrantes, movilidad $y$ segregación socio territorial en la ciudad de Maldonado. Estigmas y construcciones subjetivas en la segunda aglomeración urbana del Uruguay. ${ }^{2}$ Ambos trabajos, son hasta el momento, según las revisiones realizadas, las únicas investigaciones disponibles sobre los impactos de la movilidad y la segregación socioterritorial en la Aglomeración Central Maldonado, Punta del Este y San Carlos (AMPESAC), desde la perspectiva de la producción de subjetividad.

Este artículo, busca poner en diálogo las narrativas de quienes se autodefinen como locales y a quienes estos engloban dentro del estrato estigmatizado de "venidos" (Gerber, 2016). Se analiza la categoría emergente de ambiente, a través de los relatos espontáneos generados sobre el mismo. Resulta particularmente relevante que en ningún caso los participantes fueron consultados al respecto. El ambiente es entendido aquí en sentido amplio, incluyendo el paisaje y aspectos del ambiente urbano como la arquitectura.

Para abordar las construcciones subjetivas, de quienes habitan este territorio atravesado por el turismo, una de las principales áreas de ocupación y árbitro de las relaciones sociales que en él se producen, es necesario considerar algunas de sus principales características.

Las comunidades receptoras de turismo, una vez que se consolidan como tales, sufren cambios en sus dinámicas precedentes. Por una parte, el crecimiento económico más general, el cambio de la matriz demográfica, la centralidad de los medios de comunicación, el aumento de la alfabetización y tecnificación (Huete, Mantecón y Mazón, 2008b). Por otra parte, deben considerarse a estos procesos y al propio turismo, como parte de los fenómenos producidos por la globalización del capitalismo (Huete et al., 2008b).

Huete, Mantecón y Mazón (2008a) coinciden con Demajorovic, Aledo Tur, Landi y Mantovani Kondo (2011) en relación a que uno de los principales impactos del turismo residencial es la transformación de la tierra en suelo, entendiendo el suelo como una mercancía y objeto de consumo hasta su total agotamiento. Para Huete et al. (2008a) el turismo residencial se caracteriza por su naturaleza fagocitadora, expresada en una necesidad de esta industria, de estar constantemente consumiendo tierras para convertirlas en espacio urbano. La posesión y control del suelo se convierten en el eje estructurante de las comunidades abocadas al turismo residencial. Su principal objetivo no es atraer

\footnotetext{
${ }^{2}$ Fase elaboración del informe final Proyecto CSIC - UDELAR. Iniciación a la investigación (Llamado 2017).
} 
directamente turistas sino producir suelo urbano para su comercialización.

Demajorovic et al. (2011) afirma que dichos procesos especulativos tienen como consecuencia la expulsión de pobladores de bajos ingresos en áreas de gran interés turístico. El turismo residencial es considerado la principal expresión del desarrollo turístico en la zona, con un importante impacto en las formas de desarrollo urbano (Acuña et al. 2013).

Toledo (2005), en referencia al desgaste que producen otros modos de avance del capitalismo global sobre la tierra, como es el caso de la agricultura industrial, dejando zonas desertificadas que luego se convierten en suelo de fábrica, advierte que la peor tragedia no es la pérdida directa de estos ecosistemas, sino la destrucción de lo que él llama la memoria tradicional. Es decir, el vínculo entre los saberes sobre esos ecosistemas y los grupos humanos que los han habitado a través de largos períodos de tiempo. En trabajos posteriores le llamará memoria biocultural (Toledo, 2008) o de modo más laxo, memoria ambiental.

El autor hace un repaso de la composición de la memoria humana. Afirma que compartimos con el resto del reino animal una memoria genética, pero si bien otros mamíferos cuentan con una cierta memoria lingüística y cognitiva, en nuestra especie el desarrollo de estas últimas es diferencial, dando lugar al cultivo de memorias colectivas y sociales (Toledo, 2008). Destaca que este ha sido el modo en que los humanos durante miles de años logramos adaptarnos al ambiente más allá de la adaptación genética que también tuvo lugar. Nuestra especie se destaca por adaptar el entorno a sus necesidades a través de largos y costosos procesos de aprendizaje transmitido a través de la memoria biocultural. Estos saberes integrales permitieron generar la diversidad de paisajes, agriculturas, arquitecturas, que dieron lugar a la diversidad étnico-cultural existente en el planeta hasta hace algunos siglos, cuya riqueza y diversidad se encuentra en riesgo como las de diversas especies y equilibrios ecosistémicos.

A partir de la modernidad occidental, se ha roto ese largo lazo de transmisión de saberes, la memoria biocultural está en peligro al producirse una vertiginosa desvinculación de las poblaciones ancestrales y sus hábitats (Toledo, 2008). Toledo se centra en la memoria de las comunidades tradicionales, no occidentales, como las principales portadoras de dichas memorias bioculturales.

Devos (2007, 2009) y Devos, Soares y Rocha (2010) sin embargo, comprende la memoria ambiental integrada al ámbito urbano. Su función es como otras memorias humanas: conservar y transmitir conocimientos prácticos $\mathrm{y}$ saberes de diverso orden. En sus trabajos de campo, en periferias suburbanas de bajísimas rentas en Río Grande do Sul, encuentra una gran inteligencia narrativa, donde la capacidad de transmitir experiencias, entreteje lo fantástico y lo creativo con diferentes aspectos de la vida cotidiana. Los elementos del ambiente natural, se urden en los relatos con el ambiente urbano y social de modo inextricable. El tiempo de permanencia y la ligazón de los lugareños con el espacio, determinan los modos en que los pobladores de las Ilhas do Jacuí, perciben las problemáticas ambientales, su entorno y construyen un sentido de pertenencia y una memoria que les permite apropiarse, o no, de ese hábitat.

Las diversas tradiciones que permiten el estudio de estas producciones de 
subjetividad, tienen algunos puntos de acuerdo. La subjetividad, lo que vivimos o experimentamos como el "yo", o la mismidad, es un producto de las condiciones socio-históricas. Esta, está atravesada, producida por las relaciones sociales en las que estamos insertos. Utilizamos aquí esta noción como herramienta para comprender cómo el fenómeno del turismo residencial, así como la expulsión de la población de los espacios que han vivido como propios, afecta la construcción de sus lazos con el ambiente desde lo que estos perciben y narran como sus propias vivencias.

Las subjetividades arrancadas de la costa son aquellas que la industria turística ha expulsado. Al mismo tiempo, que el propio desarrollo capitalista dinamiza este rubro, va dejando otras zonas del país sin posibilidades de empleo, estimulando la migración campo-ciudad, y a las ciudades intermedias como es el caso de Maldonado.

Para la escuela francesa: "el pliegue de la línea del afuera es lo que se llamará zona de subjetivación o el sí mismo (...) es decir el interior del exterior" (Deleuze, 2015, p. 194). La subjetividad, en tanto proceso como producto, es "concebida de forma inacabada y múltiple, incluyendo una instancia de creación radical en el fondo de [un] 'sujeto desfondado' o 'abierto'" (Álvarez Pedrosian, 2011, p. 129). Las sedimentaciones de la experiencia, sus diversas amalgamas, pliegues, repliegues y conmociones, van dando lugar a la emergencia de estas múltiples formas de hacer y ser que sólo pueden ser abordadas desde sus instancias productivas, en acontecimientos y estares.

De forma, que la subjetividad puede ser aprehendida de diversos modos, pero cuando intentamos dar cuenta de procesos subjetivos que están aconteciendo, sólo podemos hacerlos a través sus acciones y enunciaciones. Prácticas cotidianas y narrativas de quienes están atravesados por los procesos de producción subjetiva que nos convocan. Este trabajo toma esta segunda vía de acceso.

"La narrativa es un arte profundamente popular, que manipula creencias comunes respecto de la naturaleza de la gente y de su mundo" (Bruner, 2013, p. 126). Tiene como principal finalidad, procesar la incertidumbre y los constantes avatares de la vida. El trabajo narrativo del yo, le permite a este modelarse, crearse, en un marco pautado por los propios parámetros de la pequeña y la gran narrativa de su tiempo y su cultura (Bruner, 2013).

Las narrativas nos permiten moldear, significar y resignificar nuestras experiencias, es sólo a través de ellas que nuestras vivencias se vuelven inteligibles y compartibles. Son el mecanismo que nos permite apropiarnos singularmente de la experiencia dándole nuestra impronta, al mismo tiempo que colectivizarlas. Se inscriben en reglas como la secuenciación temporal y la construcción de un hilo argumental. Estos convenios sociales-subjetivos y subjetivantes-las hacen posibles. Resulta relevante atender a su potencial generalizador (Finnegan,1998).

\section{Material y Métodos}

Los detalles relacionados a la estrategia metodológica utilizada en el primer 
trabajo (Tesis de Maestría en Psicología Social) pueden encontrarse en Gerber (2016). Las principales herramientas de recolección de datos fueron la observación participante y las entrevistas en profundidad. Los elementos coincidentes entre ambos trabajos, fueron los diseños metodológicos cualitativos y flexibles (Valles, 1999) y el uso de la entrevista en profundidad, así como la pregunta inicial disparadora del protocolo de entrevista.

El diálogo se iniciaba con ¿cómo es vivir en Maldonado? y en ambos casos se consultaba por la percepción de la convivencia entre los diversos colectivos que habitan o circulan por el territorio, aunque en momentos diferentes de la entrevista, en caso que dicha respuesta no surgiera de modo espontáneo.

Del material de campo del primer trabajo se incluyen únicamente los relatos de aquellos participantes que se auto identifican como locales o nacidos y criados en Maldonado-Punta del Este. Dado que este grupo que ha sido expulsado de la costa por el turismo residencial, responsabiliza de los problemas urbanos que sufre, a la migración de bajos recursos. Incluso si se les pregunta explícitamente, con contadas excepciones, responden que han sido expulsados de sus espacios de pertenencia por "los venidos", o de modo más general por el crecimiento demográfico (Gerber, 2016).

En el caso de la segunda investigación, esta se centró en la reconstrucción de narrativas biográficas. Se realizaron para ello un total de 26 entrevistas semiestructuradas a abiertas, que permitieron realizar un total de 11 biografías de residentes arribado/as en momentos y de formas diferentes, a tres barrios previamente seleccionados. Dos asentamientos irregulares "Los Eucaliptus" y "Kennedy" y un cordón urbano: el "Balneario Buenos Aires". Este último, se extiende más de tres kilómetros sobre la ruta 10, con importantes áreas de ocupación precaria.

Cabe resaltar que las entrevistas realizadas a los participantes en uno y otro trabajo fueron de extensiones y metodologías diferentes, pero el resultante análisis resulta consistente por su condición de categoría emergente.

\section{Resultados}

"Esto no era nada. Era arena, médanos, apenas unas calles de balastro y cuando había viento, se tapaba"

Para mi esta zona, Maldonado, Punta del Este, es lo que ha formado a mis abuelos, a mis padres y a mí, con el trato de tres generaciones, con una población flotante (...)

No confundir servicio con servilismo (...) Acá no conocemos otra cosa, en esta zona que el trabajo relación al turismo. (...) tenemos que ofrecer buen trato, ofrecerle servicios y toda la ayuda que podamos, porque nosotros sacamos un beneficio de todo eso, significa un retorno en dinero.

Mis padres fueron los primeros pobladores de acá, de La Pastora. La gente cuando podía tener algún dinero, compraba acá, pero esto era arena, médanos, apenas unas calles de balastro y cuando había viento, se tapaba 
de arena. Eran médanos. La gente iba empezando con un modesto rancho.

El turismo salía a cabalgar por esta zona (...) Esto era todo monte, aquí, donde tenemos algo que ha cambiado Punta del Este, que es el Conrad, ahí había, que está entubado, está bajo tierra, un arroyo; le hicieron, todo el basamento del Conrad son piedras, entonces, el agua corre por debajo y sale en el mar, menor proporción que antes, pero sale. Y ahí, mi madre cuenta que se lavaba la ropa, en esa corriente de agua dulce, que no era agua contaminada, se lavaba la ropa e incluso, se juntaba la verdura, berros.

Y esto no era nada, Punta del Este, como todo lugar que se inicia, no tenía esta explosión demográfica como ahora. Fue algo más pausado, hasta que se vio que esto tenía futuro, que se compraba barato, que se invertía dinero, limpio o no, pero Punta del Este permitió todo eso. Ya te digo, esto era nada.

Fíjate que mi abuela pasaba el rastrillo en la arena, en la playa Mansa (...) Los niños de la vuelta, conocidos de ella, sabían que hacía el trabajo, andaban con ella porque al pasar el rastrillo aparecían juguetes, que los niños de Punta del Este no teníamos...

Acá hay casitas, quedan algunas en... queda algo. Las torres han desalojado a la gente de Punta del Este, porque le han permitido comprarle la propiedad (...) Maldonado o cercano a Maldonado y hacer una diferencia para poder vivir. Yo sigo viviendo en la zona porque, no acá, yo vivía acá también, pero ya vivo un poco más lejos, pero estoy en Punta del Este. Tuve una propiedad y me corrieron porque me la querían comprar, comprar, porque necesitan, bueno me hicieron tremenda torre al lado quedé a la sombra, la tuve que vender, vivo en un apartamento. Acá, eran todos familiares (...) han ido desapareciendo... el dinero, el poder del dinero. (R. Tatisba, comunicación personal, 6 de setiembre de 2013) ${ }^{3}$

Tenemos aquí a nuestro primer informante, se trata de Ricardo Tatisba. Al final de la entrevista Ricardo continúa charlando aún con más entusiasmo, cuenta anécdotas de su niñez y adolescencia, refiere a la sensación de pequeñez frente a la naturaleza, la insistencia de los médanos, la lucha para que las casas no fueran "absorbidas" por estos. Evoca sensaciones que están muy vivas en su memoria, recuerda que se sentía de otro modo el olor del mar y la fuerza del viento, que "chiflaba y se metía por cualquier rendija". "Yo cierro los ojos y es como si estuviera ahí, a veces miro a mi alrededor y me parece mentira que no quede prácticamente nada de todo aquello".

El relato de Ricardo nos lleva a ensamblajes, mediaciones y tensiones entre agentes humanos y no humanos (Latour, 2001), completamente distintos a las que se pueden constatar en el presente. Vale resaltar que tanto el paisaje como las distancias que Ricardo evoca, resultan difícilmente representables para el espectador foráneo y pone de manifiesto la vertiginosidad en las transformaciones del ambiente que confirmaran todos y cada uno de los entrevistados pertenecientes a su grupo.

\footnotetext{
${ }^{3}$ Para preservar su identidad los nombres de los informantes han sido cambiados.
} 
Ricardo se siente orgulloso de pertenecer a una familia que ha trabajado a lo largo de cuatro generaciones, incluyendo a sus hijos, con el turismo. Sin embargo, siente que tiene que defenderse de un posible agravio: el de "servil". ¿De dónde proviene tal acusación? No hubo ninguna charla previa, se encuentra respondiendo a la primera pregunta del protocolo de entrevista: "¿cómo es vivir en Maldonado?" Por este motivo es particularmente fértil la pregunta. Es interesante la explicación que él mismo ofrece al respecto: "nosotros ofrecemos servicios", "atención a cambio de algo", "el buen trato al turista, significa un retorno en dinero", junto a la afirmación tajante: "acá no conocemos otra cosa (...) que el trabajo en relación al turismo". Podemos pensar que nos encontramos cerca de un núcleo que anuda tanto el orgullo como la vergüenza (Honneth, 1997), del que emerge un cierto dolor subjetivo. Puede entenderse así esta tendencia a la clausura, a afirmaciones absolutas que se pliegan sobre sí: "no conocemos otra cosa".

Los dolores subjetivos y las contradicciones que atraviesan a Ricardo son varias. El deseo de conservar su vivienda en la zona de la Pastora que la especulación inmobiliaria no le permitió, parece ser uno de los elementos más significativos. Su consuelo es haber podido hacer, como otros, "una diferencia" en términos monetarios. Podríamos preguntarnos si todas estas pérdidas de espacios y el estar al servicio de otros puede ser siempre compensado con dinero, si alcanza o son necesarias otras reciprocidades. Él mismo desliza en un momento "el dinero, el poder del dinero", parece querer dar cuenta de cierto sometimiento a la hegemonía de este, por sobre otros valores o formas de intercambio.

El párrafo que se inicia con la afirmación "Esto no era nada" parece condensar, como contrapartida, lo que entiende por ser algo en nuestras cosmovisiones occidentales dominantes y dentro de un esquema mercantil. Acarrea, por tanto, toda una concepción del ambiente y el desarrollo que retomaremos más adelante. A la concepción del mercantil se suma, la de "dinero limpio o no", legítimo o ilegítimo y la de crecimiento. La cadena asociativa parece estar armada más o menos del siguiente modo: comprar-vender-dinero limpio igual a tener futuro-dejar ser nada. Por dejar de "dejar ser nada" podríamos decir "mera naturaleza".

\section{“La Laguna del Diario antes conectaba con el Mar, se rodeaba por afuera por Lussich"}

Para mi vivir en Maldonado es bárbaro, realmente es bárbaro a pesar de los cambios que se han sucedido por la cantidad de gente que han venido, que cambian, que cambiaron la estructura (...) Vino mucha gente a vivir, a buscar trabajo, vino gente buena y de la otra. Mucha gente de repente con buenas intenciones, pero de nivel bajo, de clase baja...

El lugar de reunión, toda la gente se reunía en el Democrático (...) El Democrático era el lugar de encuentro, nada más y nada menos, que del encuentro de los mozos y las mozas... de los primeros coqueteos. Y yo creo que, tal vez, alrededor del año 49, todavía estaba más o menos en orden.

En la parada 2 también había gente, medio desparramados, de ese lado, ya, 
pero uno, a veces iba... Yo me acuerdo que un martes que fui de casa hasta La Estación, creo que sí encontré un perro, es mucho. Sí, estaba la farmacia Musso, en frente de la escuela, estaba interrumpiendo un poco el descampado.

La escuela estaba en el mismo lugar que está hoy. Pero cuando yo era chico, chico, la escuela era ahí, en el Democrático, que no era Democrático porque era escuela, que ya se llovía y mudaron la escuela para acá y para allá, y después fue el Democrático, otro despelote. Después lo alquilaron para un restorán... Y entonces, hicieron esta otra escuela y ahí eso se acomodó.

Por el año 49, me acuerdo que tomé un ómnibus que me llevó cinco horas para llegar a Montevideo de acá, porque entramos por afuera, entramos... La Laguna del Diario antes conectaba con el Mar, se rodeaba por afuera por Lussich. Esa vez que fui yo iba por la laguna del Diario, como estrenándola, digamos. Cuando me fui a estudiar. (A. Gusmán, comunicación personal, 24 de julio de 2013)

Alfonso realiza un enorme esfuerzo para representar esa Punta, esa península que fue la de su infancia y juventud. Busca dar elementos para orientar, marcos de referencia del hoy y cuando cree encontrarlos, ya no están más allí. Es el caso del establecimiento del Club Democrático que se transformó en el Club Punta del Este y entre tanto fue alquilado para ser un restaurante; hoy ya no es ninguna de las tres cosas y debe valerse de otras muchas referencias para tratar de situarse y situar al interlocutor.

Las referencias se van corriendo de su sitio hasta perderse o volverse, en sus palabras, "un despelote". El club social se mezcla en el establecimiento con la escuela, dos instituciones de referencia para él. Entre ellas llega a inmiscuirse la especulación inmobiliaria, dado que el establecimiento se alquila para la industria gastronómica, otro de los pilares de la industria turística local. Finalmente, este se deteriora, se vende y nuestro informante le pierde el rastro. Podría ser la historia de muchos inmuebles de la península que algún día albergaron una institución valiosa para los locales.

Las prácticas sociales se han transformado, junto a la arquitectura y a los modos en los que la península ha sido y es habitada. Según Alfonso, ya casi no quedan familias residiendo allí de forma permanente, ninguna de las que él conoce, y es buen conocedor de los lugareños. Él se mudó a un pequeño barrio privado dentro del municipio de Punta del Este, próximo al límite con Maldonado. De todos modos, subjetivamente, él se sitúa en Maldonado. La desurbanización, en el sentido que le da Lefebvre (2017) a esta noción, es clara: a pesar de ser una pequeña villa, ésta contaba con una serie de espacios en los que la arquitectura, el paisaje y las prácticas cotidianas producían, una rica trama socio espacial.

En su reconstrucción narrativa del espacio, lo único que logra instituirse es la escuela pública. Ésta, una vez que obtiene su propio local, permanece en el mismo sitio como un punto de referencia confiable en medio de tanta evanescencia.

En la charla posterior a que se apagara el grabador, Alfonso cuenta que la abuela de Tatisba rastrillaba la playa de la Punta junto al Puerto. Esa que hoy ya no 
existe. Alfonso se las ingenia para hablar mucho de las que vive como sus pérdidas ambientales, pero fuera de micrófono. Así revela con melancolía la existencia de "la playa sepultada". Una playa que para su generación fue muy significativa, donde se daban clases de natación para los más pudientes, al tiempo que los jóvenes locales aprendían a nadar enseñándose mutuamente. Playa que los forasteros no logramos imaginar en el rincón de la rambla, reducida bajo el asfalto y el cemento. Sobre ella luce la loza del embarcadero de yates y otras embarcaciones deportivas del Puerto de Punta del Este.

Por otra parte, Alfonso hace referencia también a esta condición de difícil acceso de Punta del Este y Maldonado, al tratarse de una zona rodeada de lagunas, humedales y arroyos, que hacía a los recorridos en ómnibus largas odiseas. Cuenta cómo estrenó el primer trazado carretero que comenzó a dividir la unión natural y lábil entre la Laguna del Diario y el Océano Atlántico.

\section{"La vida allí entre la arena y el mar era todo luz"}

Cuando nosotros llegamos había muy poquitas familias ahí, contadas, contadas. La gente que venía, la gente pudiente de San Carlos, que tenían sus casitas, eran para el veraneo. La Barra era como un pueblito de pescadores.

Yo me acuerdo de venir a Maldonado o ir a Flores con mi madre y ver gris, todo gris. Porque claro, la vida allí entre la arena y el mar era todo luz. Vivíamos como unos bichitos, digo yo... porque era con casi nada que vivíamos. Las casas eran ranchos. Las familias de la Barra eran más que humildes. La mayoría de ellas eran pobres, comían pescado, sacaban agua de los pozos.

El puente primario, era de madera, después se rompió, duró hasta el año 56 me acuerdo. Sí, después le hicieron el otro igual. El de madera. Se rompió. Lo hicieron mal ese puente, y lo comió el teledo. La madera mal curada. Después restauraron el viejo. El viejo de madera que lo había malogrado una creciente (...) pasábamos caminando por ahí porque no dejaban pasar con el ómnibus lleno.

En la casa que tuvimos camino a Manantiales no había calle, eran médanos, médanos. Papá estaba plantando ahí. Forestando para un hombre, imagínate, plantitas, entonces, para ir a Manantiales, había que ir por la playa. La Laguna Blanca, se abría, cuando se llenaba mucho de agua, se abría para la playa, entonces, ahí no dejaban pasar.

Los primeros viajes que vinimos a Maldonado me acuerdo que la maestra nos premiaba, por ejemplo, si hacías bien una cosa, entonces, de repente, me ganaba un paseo a Maldonado. Yo qué sé, entonces, era para nosotros la fiesta máxima.

Nos vinimos a Maldonado cuando me casé porque no había trabajo, buscando progresar. Porque acá, en la construcción era el furor, dentro de todo. Allá no había trabajo era poco y para que John y Mirta fueran al liceo. Era otro Maldonado, ahora se ha vuelto más peligroso cambió... 
Ahora cuando vuelvo a mí me da tristeza, hablaba con la hija de la maestra que crecimos juntas, y le decía: siento que nos quitaron muchísimo, como que aquello, ¿sabes qué?, como cuando la civilización agarraban a los indios, supongo que todos habrán sentido lo mismo (...) muy lindo el progreso pero no sé, hay cosas que no sé, la Laguna Blanca ni llegar se puede, y aquella Laguna pensar que era nuestra (...) como que ha sido una invasión, nos han quitado aquello, todo aquello que era de nosotros, nuestra playa, nuestras cosas. Como que vino una invasión y se lo llevó. (C. Rayel, comunicación personal, 20 de junio de 2013)

Resulta difícil agregar palabras a lo narrado por Chela, sin duda su testimonio es uno de los más elocuentes. Pautado por una trayectoria vital muy particular: su padre, peón de una empresa forestal, se instaló en la Barra y luego en la zona cercana a donde hoy se ubica el hotel Mantra, con su prole, cuando esta contaba con hábitats naturales con poca presencia antrópica. Espacios que nuestra entrevistada describe con una nitidez incluso perceptiva: "entre la arena y el mar era todo luz". La distancia social, subjetiva y material que se establecía entonces con Maldonado y entre La Barra y Manantiales quedan muy claros, al igual que el esfuerzo que suponía para los humanos sobreponerse a los desafíos que planteaba el ambiente.

Sin embargo, lo más significativo para este trabajo es la interpelación directa que Chela llega a hacer de la idea de "progreso", este que ella vino a buscar a la ciudad pero que, una vez que vuelve a "su lugar" al que ella experimenta subjetivamente como el espacio propio, siente que él mismo ha sido expropiado, colonizado y que no quedan más que restos ambientales y sociales de aquel.

\section{“Maldonado era como vivir en un paraíso"}

Acá vivimos del turismo, más que nada. Hay una sola cosa que yo no puedo ayudarte, no sé, cuántos habitantes tenemos en este momento.

Para mí, que soy nacida y criada acá, es, era, no sé si hablarte de ahora o de antes. Vivir en Maldonado era como vivir en un paraíso, porque tú salías, dejabas la puerta abierta, todos nos conocíamos, necesitabas algo, estaban presentes todos, en las buenas, en las malas.

El Maldonado actual, tienes que estar con reja, trancada, hay robo, hay crimen, hay de todo. Es precioso Maldonado, pero esa la inmigración que ha venido, gente que ha venido de otro lado, pero el problema acá, en Maldonado, es uno solo; como te dije. Se vienen en verano acá a trabajar la temporada. ¿Qué pasa? Se van quedando, entonces, no tienen donde vivir y empiezan a hacer asentamientos. La inmigración pasa años para que los puedan sacar y para sacarlos, ellos piden que se les haga una casa. Si yo fuera un comisario, llegó la temporada, no tiene nada, te mando para tu a casa. Entonces, estamos saturados de gente por eso. ¿Tienen el mismo derecho? ¡No! Al no tener casa ni nada, se vuelve muy peligroso esto.

Maldonado antes, la gente, por ejemplo, los domingos, la gente católica iba a la iglesia a las once y después se reunía la familia toda y, por ejemplo, iba a 
casa de los suegros, otro día a la casa de los padres, pero siempre había unión familiar; toda la familia iba ahí, se reunía. Después, por la tarde, si era verano, se iban a la playa o se hacía un paseo y a eso de las siete de la tarde, en la plaza tocaba la banda, entonces, se llamaba "La retreta". Ese era el Maldonado de antes. Era un paraíso.

Ahí, ahí fueron mis amores, la Farmacia Tamita, ahí era ir al liceo. En el año 41 empezaron a hacer el liceo allá donde está el Departamental. Hubo un lío bárbaro, porque se consideraba que era campo afuera aquello. Que cómo iban a ir las jovencitas en aquella época a un lugar así. Pero ese hombre era visionario, "cómo los chiquilines van a ir al monte" decían...

Pasando por ahí por La Torre del Vigía, tú sabes que antes, donde está ahora el Sanatorio Mautone, eso era todo arenal, había calles, pero estaba rodeado de arenales, ahí había, llegaba el verano y los ómnibus no podían pasar porque había turberas y con el calor se prendían fuego y el humo y las llamas llegaban a la carretera. Se prendían todo de abajo, se incendiaba con el calor del verano. Entonces, decían: "hoy no vayas, porque están ardiendo las turberas". Era un tema típico de los veranos. También no se podía llegar a San Carlos porque no había paso por el camino Lavagna.

Con las casas, aquí no ha habido ninguna preservación, con lo importantes que son esas cosas, quedan pocos lugares. Ahora, son todas cajas de zapatos de vidrio (...) (C. Del Puerto, comunicación personal, 20 de setiembre de 2013)

Coca nos pinta un paisaje desde Maldonado ciudad con pocos matices. De algún modo, entre el infierno y el paraíso. Sacraliza el Maldonado de antes, de buenas costumbres y ve a un Maldonado "descarriado" por la llegada de los trabajadores zafrales. Plantea que la pobreza, se vuelve muy peligrosa y por tanto debiera ser "desterrada". Esto coincide con acciones efectivamente realizadas en la zona por diversas gestiones e instituciones.

Estos modos en los que, desde un cierto posicionamiento subjetivo, la alteridad es construida, narrada y tratada en Maldonado, como un resto, una otredad radical a la que se le niega su condición ciudadana, ha sido analizado en Gerber (2016). Resulta significativo aquí resaltar que se deposita en los "venidos", en particular en aquellos socioeconómicamente más desfavorecidos, la "degradación del paraíso". Coca es quien lo expresa de modo más radical, pero se trata de un elemento que atraviesa los relatos de este grupo.

Al mismo tiempo que estigmatiza de este modo a los migrantes, se muestra crítica con lo que fue el chovinismo local de su época. Éste, consideró en su momento, una locura la construcción del actual establecimiento del Liceo Departamental de Maldonado. Una vez más aparecen distancias que eran muy distintas al cambiar la naturaleza de los ensamblajes entre los elementos humanos y no humanos del ambiente.

Nuevamente nos encontramos con un ambiente de médanos, de corrientes de agua dulce que no se dejan doblegar fácilmente y que imponían su ritmo a la vida humana, que fueron el encanto y el atractivo de estas tierras pero que al 
mismo tiempo también se las trató como el escollo a superar. En este caso el testimonio nos permite comprender que el cordón dunar llegaba hasta las inmediaciones del Sanatorio Mautone y el actual parque La Loma, zona completamente urbanizada. A más de un kilómetro de dónde los escasos médanos de la playa Mansa son interceptados por la rambla de Punta del Este.

En relación con la arquitectura urbana, Coca nos cuenta que "no ha habido ninguna preservación". Es interesante el término elegido, cuyo antónimo es la extinción, de uso habitual en el ámbito de los estudios y movimientos ambientales. Describe en detalle-aquí por cuestiones de espacio se transcribe un párrafo corto-como las viviendas y casas de estilo colonial, que para ella tienen historia, nombres de familias, de las que conoce toda su trama, quiénes eran, quién se casó con quién, cómo eran los zaguanes, etc.; son demolidas sin más, y en su lugar se coloca "una caja de zapatos de vidrio". En alusión al estilo arquitectónico de los locales comerciales del centro de Maldonado.

\section{"Donde está la terminal, yo pescaba renacuajos..."}

Estos últimos años, por ejemplo, donde, en realidad, la principal riqueza está en manos de la construcción, hubo cifras récord de construcción...

Yo, al principio, cuando recién me volví, paraba mucho en el Jazz Café, veía cómo la gente se sentaba y hablaba todo el tiempo de mover tierra con camiones: yo tengo excavadora, yo tengo... todo el tiempo hablaban de mover arena o sacar tierra o de cortar árboles. Era una cosa, como de permanente modificación del territorio.

(...) vos, de chico te acostumbrás a que las cosas nunca son las mismas, a que no sé, donde está la terminal, yo pescaba renacuajos. 0 sea, te quiero decir, los espacios inmediatos de mi casa siempre han sido modificados, no hay nada que se parezca a lo que había. Es un poco algo a lo que te acostumbrás acá, a la transformación.

En la etapa liceal, tenías novio de verano y novio de invierno; te diría que de verano no tenías novio, pero vos hibernabas con una especie de novio que era compañero del liceo. Eso era una institución, ya te das cuenta cómo las relaciones ya se establecen, desde la adolescencia, así, todo depende de la temporada, inclusive, tu mundo afectivo, sexual...

¿Viste cuando el primo bobo de la familia se hace millonario?, eso es lo que hemos visto acá. Como que se valoriza, no sé, te das cuenta cuando ves dentro del sistema político, la calidad de los ediles, lo que dicen en la Junta, donde vos decís: acá hay un desprecio absoluto a la cultura, al pensamiento.

Describir Maldonado es muy difícil, yo tengo una percepción de la ciudad de Maldonado como una cosa más bien fea, rodeada de una serie de cosas muy hermosas, principalmente, por una notoria escasez cultural en su parte urbana, hay como una pobreza que no se ve en otros lugares. 0 sea, vos vas a Aiguá y la sensación que vos tenés de lo urbano es mucho más estimulante visualmente. Y acá la integración entre el paisaje humano y el paisaje construido es bastante pobre, o sea, acá es un sitio donde no hemos podido 
conseguir un respeto, ni a esa pequeña villa pobre que fue originalmente, que la hemos, de alguna manera, avasallado. San Carlos es una cosa distinta, (...) hay una cosa propia en lo urbano y una dinámica cultural distinta. (T. Coutinho, comunicación personal, 17 de julio de 2014)

Podemos considerar que Toña, por su capacidad de reflexión, es una voz peculiar, que mira su realidad desde ángulos diferentes. Sin embargo, aunque pueda describir y problematizar lo que le acontece, no deja de compartir con los demás este componente de dolor subjetivo. Quizás esto se vuelva más evidente en su relato a través del enojo, cuando dice: "¿viste cuando el primo bobo de la familia se hace millonario? Eso es lo que hemos visto acá". Si ligamos esta afirmación con sus referencias a la desvalorización de lo cultural, a cierto vaciamiento de todo aquello que no es la temporada, podría coincidir desde una narrativa crítica con lo que Tatisba describe desde la linealidad como el "poder del dinero". Diversos ámbitos de la vida laboral, habitacional, urbana, cultural, ambiental pero incluso aquello que ella describe como un "mundo afectivo, sexual (...) condicionado", atravesado por momentos, avasallados en otros, por las dinámicas de la temporada que es sinónimo de turismo.

Resulta interesante atender como "el poder del dinero" tiene una capacidad de mover tierras, cortar árboles o incluso afectar los vínculos de modo singular en estas costas. ¿Podríamos pensar en dinámicas de estas características en el resto del territorio uruguayo?

Toña resalta que "los espacios inmediatos [a su] casa siempre han sido modificados". A partir de los impactos en las subjetividades de nuestros informantes, podemos afirmar que "el poder del dinero", la fuerza con que el capital, favorece la multiplicación de redes de mediaciones técnicas ${ }^{4}$ que se transforman a una velocidad (Latour, 2001) única, si tomamos como referencia el territorio nacional en el que se inscriben.

Toña hace una descripción de la desurbanización (Lefebvre, 2017) de la ciudad de Maldonado que toma dicho eje. Coincide desde su crítica, con la mirada conservadora de Chola, una fuerza "afea la ciudad". Es significativo el contrapunto que hace con los núcleos urbanos no costeros como Aiguá y San Carlos. Los locales comerciales arrasan con la identidad estética de la ciudad, no hay espacios para "lo cultural", dice Toña, sólo para los locales comerciales.

Hasta aquí hemos escuchado a quienes se autoidentifican como fernandinos. Resulta importante escuchar la voz de las subjetividades que han sido arrastradas a la costa en búsqueda de diversos proyectos, en general de una mejor vida para sí mismos y para los suyos. ¿Cuáles son sus experiencias?

\section{“Estaba hermoso, estaba así verde por todos lados (...) lleno de ratas, pero convivían con nosotros"}

Después fuimos para la Casona, en Dodera, ahí que nos habían dado para

\footnotetext{
${ }^{4}$ Aquí no hacemos un uso puro de la Teoría del Actor Red (TAR) para la misma no habría actores humanos puros (Correa, 2012).
} 
vivir. Una propiedad vieja enorme que hay. ¡La rata más chica era del tamaño de la mesa! Es de la época colonial. Ya teníamos a todas las niñas, Liliana era chiquita, tenía meses. Esa casa de todas las que vivimos hasta poder levantar la nuestra, fue la que más quisimos. Antes entrábamos por la puerta principal, pero después cuando el dueño puso el comité y arreglamos el otro lado. Entonces nosotros nos quedamos cuatro piezas, pero piezas ¡enormes! entonces yo levanté las rejas de una de las ventanas, la levanté con unos palos (...) Entonces hice una escalerita (...) estuvo genial. Aparte habíamos limpiado todo el fondo, estaba así verde por todos lados. ¿Viste? Árboles. Palmeras.

Lleno de ratas pero convivían con nosotros, fue la primera vez en años que volvimos a tener espacio, algo verde, lugar para movernos. Años y años todos amontonados. Pagando alquileres altísimos. Ahí no estábamos ahogados.

Cuando vimos que habían talado parte esos árboles y querían tirar la Casona nos dolió como nuestra.

Cuando podíamos veníamos (...) la construcción nos llevó poco. Imagínate que empezamos en noviembre del 2012 y en marzo nos mudamos. Las chapas (...) son todas usadas.

No podíamos rellenar tampoco porque no teníamos plata para rellenar. Con los mismos árboles y todo eso, incluido, hicimos toda la plataforma abajo y después le pusimos chapón arriba. Tengo fotos de Rosina de madrugada, estábamos acá, y Rosina durmiendo en el suelo, y tá... yo metiéndole. No teníamos luz, no teníamos agua...(M Lema, comunicación personal, 20 de noviembre de 2018)

$\mathrm{Y}$ a las 7 entraba a trabajar, pero era la forma de poder venir y adelantar algo. Pero poder mudarnos fue una cosa que no lo podíamos creer. Las cosas todavía estaban en obra. Pero despertarme acá en mi casa entre los árboles, que también son parte de la casa, escuchar los pájaros, no tengo palabras para decir, tener lugar para mis hijas... [se emociona] (R. Gómez ${ }^{5}$, comunicación personal, 20 de noviembre de 2018)

Resulta relevante el valor que para los Lema- Gómez cobra el ambiente y el espacio. En un doble juego.

Primero, la experiencia de La Casona de la calle Dodera, en la que un caudillo local les permite vivir en parte de una vivienda abandonada, que limpian y vuelven habitable, mientras el resto hace las veces de comité. Allí tuvieron que convivir con ratas y convertir una ventana en puerta. A pesar de tener una bebé de meses, tal esfuerzo se trata de una experiencia de desahogo y felicidad. Luego de la asfixia producida durante una década por el costo de los alquileres y la falta de espacio, dentro y fuera de la vivienda. En la Casona tenían: "piezas, pero piezas", "un espacio verde" y "palmeras".

\footnotetext{
${ }^{5}$ Esposa de Marcos Lema, vecinos ocupantes de tierras del Balneario Buenos Aires.
} 
Luego, el proceso de construcción de la vivienda en el que queda muy claro el valor que cobra lo ambiental en la conquista de una mejor vida. El uso por necesidad de elementos reciclados del entorno y el afecto que la familia va tejiendo con ese espacio. Luego de años de encierro en viviendas que les resultan impropias para la vida, "aquello no era vida" repite Marcos, a lo largo de una extensa narrativa biográfica, de la que aquí se rescata solo un pequeño fragmento.

Subjetividades doloridas que van encontrando un cierto alivio al poder proveer una vivienda a su familia, pero sin los males del alquiler de espacios, que les sometían al hacinamiento y la doble jornada de 8 horas para solventarlo. El costo de este alivio es el de cargar con el estigma de "ocupas".

Al mismo tiempo, su apego a La Casona de la calle Dodera les hace sentir como propio dicho sitio con gran valor histórico- patrimonial para la ciudad de Maldonado y que ha estado descuidado y bajo amenaza de demolición durante varios años.

\section{“Salgo como a descubrir callecitas (...) una pitanga florecida..."}

Mi llegada acá a los dieciocho años, un veinte de diciembre creo que fue, estábamos así con mi hermana, no teníamos un mango (...) Recuerdo que llovía, nos vinimos a dedo, (...) a dedo y con una perra de ella, llamada Cuba. Hicimos dedo a la salida de Minas, con la bicha y todo, nos levantó un camión de mudanzas...

Me siento en casa en el barrio, hay mucha autoconstrucción, los fines de semana siempre escuchas ruido a herramientas, es gente levantándose su casa. No cambia demasiado de la temporada de verano al invierno porque justamente, o sea somos toda gente de trabajo.

Los espacios que más disfruto, quizá por la historia mía de vivir en muchas casas, es mi casa...

Lo que siento que llevo conmigo es lo de los caballos, cuando me vine para acá lo primero que empecé a extrañar fue no tener un caballo, no tener la parte esa de campo (...) capaz que te metés por calles que antes no te metías porque vas a caballo, que ves un caminito y te metés... es una libertad como muy...mansa, meditativa a paso de caballo, con el movimiento que te lleva el propio animal y ese movimiento, que es medio cadencioso, el silencio, después ves una casa, o este arbolito, oh! mirá una pitanga florecida...el monte de Manantiales que todavía está bastante agreste, ir ahí a juntar hongos y a juntar piñas, ir a caminar nomás y llegar a la Laguna, pasa que son todos naturales... son lugares sanadores, de rescate. (M. Loutre, comunicación personal, 19 de noviembre de 2018)

Margaretta experimentó una trayectoria personal de muchas pérdidas, no sólo de construcciones y proyectos, sino incluso de seres queridos en condiciones complejas que no se detallan aquí. Sin embargo, queda claro que una de sus principales terapéuticas está vinculada a la relación solidaria e integrada que sostiene con todo su ambiente humano y no humano, su modo de comprenderse como parte de él. Ella lo resume diciendo que el monte, el mar entre otros son 
espacio de "rescate". También su casa realizada en bioconstrucción por ella misma, y de la cual no podrá ser desalojada, como sí lo fue de otras.

Para ella, que se preserven espacios donde poder juntar hongos, y encontrarse en conexión con el ambiente "agreste", es importante, tiene un claro registro de cómo dichos espacios se encuentran bajo cierta amenaza.

\section{"Después que cortaron los árboles ahí en la isla, como que ya no fue lo mismo"}

Después que cortaron los árboles ahí en "La Isla", como que ya no fue lo mismo, ¿no? era un lugar para mi re importante...

Hasta una canchita llegó a haber ahí, abajo de los árboles yo tengo la foto y todo. Además de la que demolieron por los desalojos, allá adentro, pero esa era de baby mismo. Los fines de semana se juntaba gurisada en pila en esta acá. Pero antes con los árboles era mucho más lindo... ahora están rellenando con escombro hasta de allá ¿sabes?... del San Rafael.

Pah, lo que más me gusta es la playa, el mar sí. Voy mucho, es como mi lugar La Brava. Pero a la 14 no bajo porque ahí tiraron La Casona. (A. Pradó, comunicación personal, 27 de enero de 2020)

Adriana pertenece a una familia que ha residido más de 30 años en el Barrio Kennedy. Es quién ofició de "portera" en el ingreso al barrio. En la primera visita me guía al corazón del barrio para señalar el verde pastizal que crece junto a los escombros de la vieja cancha de baby fútbol e inmediatamente después se dirige a su lugar favorito: "La Isla". Esta se destaca por su follaje verde entre los ranchos de este espacio, intensamente "amado y sufrido", según relata. Desde su perspectiva, el estar rodeado de "bosque" hace más vivible este barrio "atravesado por tantas violencias". Considera el cerramiento del Parque Municipal el Jagüel, "un acorralamiento más" para los vecinos, que siempre habían vivido muy entrelazados con dicho espacio. La caminata finalizó frente a un predio baldío que, desde principios del 2000, ella, su familia y algunos vecinos, buscan evitar que se convierta en un basural, y en el que han armado una placita.

Cuando al final de la ronda de entrevistas, casi diez meses después, nos sentamos a conversar con Adriana, esta vez con intención de reconstruir su narrativa biográfica, cuenta que cortaron los árboles de "La Isla". Buena parte del terreno de la placita lo están rellenando con escombros del Hotel San Rafael, recientemente demolido. Todos hechos que pueden constatarse con solo mirar alrededor. Adriana relata en su larga narrativa biográfica, experiencias de violencia y "agravio moral" (Honneth, 1997) por parte de diversos agentes estatales, en particular del cuerpo policial, que despliega asiduamente en el barrio acciones reñidas con el Estado de Derecho (Gerber, 2021). Sin embargo, la violencia implícita en la continua degradación espacial, por acción u omisión de las autoridades competentes, en particular de los espacios públicos o comunes, son otro de los elementos significativos a los que los habitantes de los barrios periféricos deben enfrentarse cotidianamente en la zona.

Resulta relevante, que más allá de sus marcas de identidad, que en lo enunciativo hacen situarse a Adriana explícitamente, y con fuerza, por fuera de lo 
fernandino y puntaesteño, demuestra apego y vinculación subjetiva con el paisaje, la arquitectura y el ambiente, no sólo de su barrio, sino también, con todo el entorno de la Playa Brava. Su duelo por la "La Casona" de la parada 14 resulta un analizador claro, esta pertenecía a quienes ella construye como sus otros, "los chetos", dueños de "los chaleses", sin embargo ello no la exime de dolor por su pérdida. El hecho de que continuamente se derribe lo que estaba para que se construya otra cosa, produce sufrimiento en Adriana, motivo por el cual ya no baja al mar, por su parada "de siempre".

\section{Discusión}

Resulta significativo resaltar que tres de los cinco entrevistados del primer grupo fueron, de algún modo, expulsados de la costa, de los espacios en los que crecieron, todo lo que les era propio, sus paisajes, las prácticas sociales que resultan indisociables de la vida cotidiana enraizada en un ambiente - que engloba los anteriores-desaparecieron. Las otras dos, Coca y Toña, narran la transfiguración de la ciudad (Lefebvre, 2017) que habitan, a puntos casi irreconocibles. Todos se sienten exiliados en su propia tierra.

La primera respuesta que podemos dar con el material recolectado es que el dolor subjetivo es producido por las transformaciones del territorio. Estas son continuas, producen un dolor constante que se lleva consigo y se naturaliza. Dicha respuesta puede complejizarse, el sufrimiento puede ser fruto de una contradicción: sentirse partícipes, en algunos casos, de la comercialización paulatina de su propio espacio vital, ese que algunos sintetizan como "del paraíso", en nombre "del progreso".

¿Pero cómo se relacionan estos sujetos doloridos con esta contradicción? ¿Qué se hace con este malestar subjetivo? Si analizamos los relatos de los entrevistados vemos que la expulsión que han vivido en términos espaciales y urbanos ha sido efectuada por las torres de apartamentos y otras formas de ocupación del suelo por parte del turismo residencial, los locales comerciales, etc. Diversas expresiones del desarrollo y avance del capital en el territorio. Sin embargo, se responsabiliza a los migrantes internos de bajos recursos por el deterioro urbano, de los conflictos socio territoriales y convivencia, como se ha analizado en Gerber (2016) y se trasluce en muchos de los relatos aquí presentados.

Del presente análisis surgen elementos novedosos, hay una memoria ambiental que podríamos considerar en peligro. En primer término, como alerta Toledo (2008) los grupos han sido separados de los ecosistemas y hábitats que les eran propios. Por tanto, el riesgo de la amnesia comienza a volverse cada vez mayor. Los saberes sobre los mismos no resultan valiosos para las siguientes generaciones, no son más que anecdóticos. Incluso la ciudad sufre una especie de desmemoria arquitectónica y socio espacial (Lefebvre, 2017).

Por otra parte, siguiendo a Devos et al. (2010), con alguna honrosa excepción, el componente colectivo, fantástico y creativo de la memoria ambiental no se encuentra presente. Podemos considerar que por el mismo motivo, a partir 
de su expulsión del territorio, la comunidad se encuentra fragmentada y la memoria aún presente, no se cultiva más que en solitario, o en encuentros esporádicos con los viejos habitantes de la comunidad agredida.

Por otra parte, nuestros entrevistados describen fuerzas que sencillamente existen y parece que han sido tan fascinantes como temibles para la humanidad desde tiempos inmemoriales, las de la naturaleza, el dilema entre convivir con ellas o intentar dominarlas con excesiva prepotencia, parece estar vinculado a antiguas tensiones (Freud, 1930). El triunfo sobre los médanos y matorrales incendiables, los humedales, las lagunas y los arroyos con sus desbordes ha ofrecido ciertas seguridades, pero ha degradado los ecosistemas, ha quitado atractivo a la zona, ha transformado el propio hábitat y finalmente parece haber acarreado un importante monto de dolor subjetivo. Este "crecimiento a alta velocidad" ha des-urbanizado la ciudad, desintegrado la tramas entre espacios, arquitecturas, paisajes y prácticas cotidianas.

Detentar una visión mecanicista y mercantil del ambiente, que es traducido a recurso, "recurso natural" apropiable, cosificable (Najmanovich, 2019) al igual que la tierra con la que se entabla una fuerte relación de propiedad, transformándola en un bien loteable parece ser parte de la dinámica. Por tanto, el mejor paisaje y los mejores enclaves son siempre pasibles de especulación y al que sólo deberían acceder quienes pueden pagarlo. Resultan por tanto impensables como bienes comunes para buena parte de nuestros participantes (Angotti, 2019).

Estos aspectos resultan ser claves para impedir hasta el momento una apropiación colectiva del conflicto, sus fuentes, así como sus posibles soluciones. La individualización y fragmentación del problema produce, a nivel de las construcciones subjetivas, enormes contradicciones, disociaciones y proyecciones en terceros de los "orígenes del desastre". El conflicto se encuentra en condición de "impensable".

\section{Conclusiones}

Más allá de los tiempos de permanencia, un número importante de los migrantes internos mostró preocupación por la preservación del patrimonio arquitectónico, paisajístico o ambiental de la zona. Algunos años de permanencia resultan suficientes para que las vertiginosas transformaciones, comiencen lentamente a ser vividas como deterioros en la propia subjetividad.

Dichas narrativas dan cuenta de trayectorias a las que estas costas le han ofrecido una oportunidad de recomposición, donde los elementos estéticos del ambiente en sentido amplio, juegan un rol preponderante. Estos aspectos deberían ser incluidos en estudios migratorios o con los colectivos más desfavorecidos, los grupos y las personas no se mueven sólo por los intereses de supervivencia, sino que también sufren y gozan estéticamente.

¿Qué sucede entonces con estas subjetividades arrancadas de la costa? ¿Qué las enfrenta a estas subjetividades arrastradas a la costa?

Se ha fundamentado que las transformaciones del territorio son continuas y producen un dolor que se naturaliza. Al mismo tiempo que la contradicción de 
sentirse partícipes, en algunos casos, de la comercialización paulatina de su propio espacio vital, "del paraíso", en nombre "del progreso" aumenta este sentimiento. Lo que permite explicar, por qué debe buscarse un chivo expiatorio. Es posible afirmar con lo desarrollado hasta aquí, que en la rompiente se enfrentan, se golpean subjetividades que, en su mayoría, desconocen las fuerzas que las arrastra.

Una hipótesis fundamentada aquí, que debería ser profundizada en futuras investigaciones, es que la principal fuerza es la del capital global, expresada en los intereses del turismo residencial. De allí que las formas de ocupación de la tierra y la vivienda sean determinantes del estigma: de lo intolerable.

Arquitecturas, paisajes y ambiente no pueden ser pensados como bienes comunes a ser protegidos por esta comunidad. Dado que estos procesos la han fragmentado profundamente. Este modelo de desarrollo no sólo ha transformado y erosionado los ecosistemas de la zona sino también, las relaciones de los grupos humanos con estos y principalmente la relación de los grupos entre sí.

\section{Referencias}

Acuña, C. et al. (2013) Aglomeración Maldonado, Punta del Este, San Carlos. Enfoques y propuestas hacia un modelo transformador. Montevideo, Uruguay: Mosca.

Álvarez Pedrosian, E. (2011). Etnografías de la subjetividad: herramientas para la investigación. Montevideo, Uruguay: LICCOM-UdelaR.

Angotti, T. (2019). Justicia ambiental y la gestión de los bienes comunes. Tekoporá. Revista Latinoamericana De Humanidades Ambientales y Estudios Territoriales. ISSN 2697-2719, 1(1), pp.19-28.

Bruner, J. S. (2013). La fábrica de historias. Derechos, literatura, vida. México D.F., México: FCE.

Correa, G. (2012). El concepto de mediación técnica en Bruno Latour Una aproximación a la teoría del actor-red. Psicología, Conocimiento y Sociedad, 2(1), pp.56-81. Recuperado de: https: //www.redalyc.org/articulo.oa?id=4758/475847407004

Deleuze, G. (2015). La subjetivación: Curso sobre Foucault. Buenos Aires, Argentina: Cactus.

Demajorovic, J., Aledo Tur, A., Landi, B.y Mantovani Kondo, A. L. (2011). Complejos turísticos residenciales. Análisis del crecimiento del turismo residencial en el Mediterráneo español y en el Litoral Nordestino (Brasil) y su impacto socio-ambiental. Estudios y Perspectivas en Turismo, 20(4), pp.772-796. ISSN: 0327-5841. Recuperado de: https://www.redalyc.org/articulo.oa?id=1807/180722696002 
Devos, R. (2007). A questão ambiental sob a ótica da antropologia dos grupos urbanos, nas ilhas do Parque estadual Delta do Jacuí, Bairro Arquipélago, Porto Alegre, RS. 2007. 275 p. (Tese Programa de Pós-Graduação em Antropologia Social). Universidade Federal do Rio Grande do Sul, Porto Alegre.

Devos, R. (2009). A crise ambiental sob a perspectiva da memória e dos itinerários no mundo urbano contemporâneo. Ambiente \& Sociedade, 12(2), pp.293-306. Recuperado Recuperado de: http://clacso.redalyc.org/articulo.oa?id=31715780006

Devos, R., Soares, A.P.M., Rocha, A.L.C. (2010) Habitantes do Arroio - memória ambiental das águas urbanas. Revista Desenvolvimento e Meio Ambiente, 22 (14), pp. 51-64. https://www.semanticscholar.org/paper/Habitantes-do-Arroio\%3A-mem \%C3\%B3ria-ambiental-das-\%C3\%A1guas-1-Devos-Paula/fd8e078e240243 d62dfff91ee22567c6ceae6b85

Finnegan, R. (1998). Tales of the City: a Study of Narrative and Urban Life. Cambridge, U.K.: Cambridge University Press.

Freud, S. ([1930] 1992). El malestar en la cultura.. Obras completas, vol. 21, pp.65-125. Buenos Aires, Argentina: Amorrortu Editores.

Gerber Comba, E. (2016). Significados y usos de la alteridad: una aproximación etnográfica a los procesos de producción de subjetividad vinculados a la movilidad geográfica en la ciudad de Maldonado. (Tesis de Maestría en Psicología Social). Facultad de Psicología, Universidad de la República. Montevideo Recuperado de: https://www.colibri.udelar.edu.uy/jspui/handle/20.500.12008/9218

Gerber Comba, E. (2021). Políticas Públicas y subjetividades agraviadas en el Este del Uruguay. Revista de Ciencias Sociales, Universidad Arturo Prat. Número especial: Políticas Sociales e Intervención, 30 (45). En edición.

Najmanovich, D. (2019). Pensar los vínculos en tiempos de pandemia. Conferencia. Recuperado de: https://www.youtube.com/watch?v=iVhCE04Uoqc\&feature=youtu.be

Honneth, A. (1997). La lucha por el reconocimiento. Barcelona, España: Crítica.

Huete, R., Mantecón, A. y Mazón, T. (2008a). ¿De qué hablamos cuando hablamos de turismo residencial? Cuadernos De Turismo, (22), pp.101-121. Recuperado de : https://revistas.um.es/turismo/article/view/48091

Huete, R., Mantecón A. y Mazón T. (2008b). La percepción de los impactos del turismo residencial por parte de la sociedad receptora. Comunicación presentada en la II Jornadas sobre Turismo y sociedad. IESA - CSIC, Córdoba. 
Recuperado

de:

https://rua.ua.es/dspace/bitstream/10045/14453/1/huete mantecon ma zon C\%c3\%b3rdoba 2008.pdf

Lefebvre, H. (2017). El derecho a la ciudad. Madrid, España: Capitán Swing.

Latour, B. (2001). La esperanza de Pandora. Ensayos sobre la realidad de los estudios de la ciencia. Barcelona, España: Gedisa.

Toledo, V. M. (2005). La memoria tradicional: la importancia agroecológica de los saberes locales. LEISA Revista de Agroecología, 20(4), pp.16-19 ISSN: 1729-7419.

Recuperado

de: http://www.leisa-al.org/web/index.php/volumen-20-num\%20ero-4/2073la-memoria-tradicional-la-importancia-agroecologica-de-los-saberes-locale $\underline{\mathrm{S}}$

Toledo, V. M. y Barrera-Bassols, N. (2008). La memoria biocultural: la importancia ecológica de las sabidurías tradicionales. Barcelona, España: Icaria Editorial.

Valles, M.S. (1999). Técnicas Cualitativas de Investigación Social. Reflexión Metodológica y Práctica Profesional. Madrid, España: Síntesis. 